\title{
Detection and quantification of warfarin in pharmaceutical dosage form and in spiked human plasma using surface enhanced Raman scattering
}

\author{
Maha A. Sultan ${ }^{\mathrm{a}}$, Maha M. Abou El-Alamin ${ }^{\mathrm{a}}$, Alastair W. Wark ${ }^{\mathrm{b}}$ and Marwa M. Azab*a,b \\ a Analytical Chemistry Department, Faculty of Pharmacy, Helwan University, 11795, Cairo, Egypt \\ ${ }^{b}$ Centre for Molecular Nanometrology, Dept. of Pure \& Applied Chemistry, Technology and \\ Innovation Centre, 99 George St., University of Strathclyde, Glasgow, G1 1RD, UK.
}

\begin{abstract}
Analytical approaches for the quantitation of warfarin in plasma are high in demand. In this study, a novel surface enhanced Raman scattering (SERS) technique for the quantification of the widely used anticoagulant warfarin sodium in pharmaceutical dosage form and in spiked human plasma was developed. The colloidal-based SERS measurements were carefully optimised considering the laser wavelength, the type of metal nanoparticles, their surface functionalization and concentration as well as the time required for warfarin to associate with the metal surface. Poly(diallyldimethylammonium chloride) coated silver nanoparticles (PDDA-AgNPs) were established as a substrate which greatly enhanced the weak warfarin Raman signal with high reproducibility. The limit of detection was calculated in both water and human plasma to be $0.56 \mathrm{nM}\left(0.17 \mathrm{ngmL}^{-1}\right)$ and $0.25 \mathrm{nM}\left(0.08 \mathrm{ngmL}^{-1}\right)$ respectively, with a high degree of accuracy and reproducibility. The proposed method is simple, economical, and easily applied for routine application requiring only small plasma samples and also could be potentially useful for pharmacokinetic research on warfarin.
\end{abstract}

Keywords: Warfarin, drug determination, Raman, SERS, silver nanoparticles and spiked plasma. scattering. Spectrochimica acta. Part A: Molecular spectroscopy, 228, [117533]. https://doi.org/10.1016/j.saa.2019.117533 


\section{Introduction}

The Food and Drug administration (FDA) estimates that the use of warfarin as an oral anticoagulant for the treatment of arterial and venous thromboembolism is prescribed to approximately 2 million new patients annually to avoid myocardial infarctions and stroke [1]. Warfarin is a long-life treatment and the applied dose varies from one patient to another depending on many factors such as age, diet and concurrent medications [2,3]. Careful monitoring of coagulation by measuring the international normalized ratio (INR) via the prothrombin time test is essential for each person on warfarin therapy. The INR should be in the range of 2 to 3 , an INR $<2$ indicates that warfarin therapy is ineffective, while INR $>4$ may cause bleeding. INR is a standardized method of warfarin monitoring, it has restrictions in identifying the factors affecting the anticoagulants such as patient compliance, resistance to anticoagulant drug interaction and food variety. Also, INR fluctuation in some patients might be risky due to the narrow therapeutic index of warfarin. Thus, research interest in effective routes for warfarin dosage monitoring is still significant [4]. The challenges of this measurement combined with the annual increase in the number of patients receiving warfarin therapy highlights the need for an assay that will allow fast, accurate and warfarin quantitative monitoring. In particular, measuring plasma warfarin concentration directly could be especially helpful for managing the treatment of patients [5].

Therapeutic drug monitoring (TDM) is performed for some drugs e.g. warfarin, in order to offer patients effective treatment reducing drug toxicity and minimalizing adverse reactions. TDM requires determining drug concentrations in a biological matrix at certain times relative to administration. Various methods have been proposed for warfarin determination, such as High performance Liquid Chromatography coupled with ultraviolet (UV) [5-7] and fluorescence[8] detectors, fluorimetry [9], ultra-performance liquid chromatography tandem mass spectrometry[10], supercritical fluid chromatography-tandem mass spectrometry [11], capillary electrophoresis-mass spectrometry [12] and electrochemistry [13,14].

Surface-enhanced Raman scattering (SERS) is an attractive technique for TDM compared with chromatographic methods since quantitative drug analysis can potentially be performed quantitatively and quickly with high molecular selectivity and at lower costs[15,16]. Furthermore, portable high-performing Raman spectrometers are increasingly available and 
easy to use by non-specialized operators. SERS measurements typically involve enhancing the Raman signal of an analyte upon adsorption onto the surface of a metal nanoparticle (NP) metal such as silver. The excitation of local surface plasmons (LSP's) by the incident laser can lead to Raman enhancement factors ranging from $10^{4}-10^{6}$ to $10^{11}$ in some special cases $[17,18]$.

Raman spectroscopy is becoming commonly used in the analysis of various tablet excipients, drug substances and packaging materials as well as identify isomers [19]. These advantages in tandem with fibre optics and microscope configurations have enabled the use of Raman spectroscopy as a quality control tool in the pharmaceutical industry. SERS has also been explored as an analytical tool for the therapeutic monitoring of drugs [20-24], pathogen detection [25], and the detection and quantification of drugs in biological samples[26-28]. However, the routine use of SERS for analysis in biofluids remains a significant challenge due to the number of experimental parameters (e.g. nanoparticle size, shape, concentration, surface chemistry) that needs to be optimized and the presence of non-specific biofluid proteins inhibiting the analyte adsorption to the NP surface. SERS has increasingly been an advanced technique used for quantitative determination with high sensitivity [29,30].

In this paper, we present a SERS technique for warfarin detection in pharmaceutical dosage forms and in human plasma involving spiking with known amounts of warfarin in increasing concentrations utilizing a portable, easy-to-use Raman instrument. The number of Raman studies of warfarin in the literature is very limited typically focusing on solid form and tablet analysis [31-33]. Even with the signal enhancement associated with SERS, the direct detection of solvated warfarin molecules (and other similar drug molecules) is particularly challenging due to the limited solubility and the requirement that the target molecule adsorbs effectively onto the nanoparticle substrate. To the best of our knowledge, the SERS warfarin detection approach developed here is the first study of its kind using custom-functionalised silver nanoparticles to detect the drug at clinically relevant concentrations and furthermore being able to also measure in spiked plasma samples.

\section{Experimental}

\subsection{Materials and reagents}

Warfarin purity (101.21\%) batch number (WA0010412) was kindly supplied by the Nile company for pharmaceutical and chemical industry (Cairo, Egypt). Marevan ${ }^{\circledR}$ tablets (MSD, 
Egypt), Batch no. M1010417, 5 mg warfarin sodium was purchased from a local market. Silver nitrate $\left(\mathrm{AgNO}_{3}\right)$, sodium citrate tribasic dihydrate, poly(allylamine hydrochloride) (PAH) (MW 15,000-30,000), poly(diallyldimethylammonium) chloride (PDDA, MW 100,000, 20 $\mathrm{wt} \%$ ) and sodium hydroxide were purchased from Sigma-Aldrich and used without further purification. Phosphate buffer solution $\left(50 \mathrm{mM}, \mathrm{pH}\right.$ 6.80) was prepared using $\mathrm{K}_{2} \mathrm{HPO}_{4}$ and $\mathrm{KH}_{2} \mathrm{PO}_{4}$, both purchased from Sigma-Aldrich. All chemicals were used without further purification. All nanoparticle syntheses were performed using Milli-Q deionized water.

\subsection{Raman detection}

All SERS measurements were performed using a portable Snowy Range Instruments Sierra series $^{\mathrm{TM}}$ Raman scanner. All data presented was acquired at $638 \mathrm{~nm}$ excitation $(\sim 15 \mathrm{~mW}$ incident power) as this was found to be optimum compared to $532 \mathrm{~nm}$ and $785 \mathrm{~nm}$. Samples were analysed using disposable glass vials, with a volume of $400 \mu \mathrm{l}$ used. A signal collection time of $20 \mathrm{~s}$ per spectra was used for all bulk solution spectra presented. Daily calibration of the instrument was achieved by obtaining the Raman spectrum of ethanol using the calibration routine built into the software. For all SERS analyses, the spectral range is 2000 to $200 \mathrm{~cm}^{-1}$ with a spectral resolution of $8 \mathrm{~cm}^{-1}$. In addition, the Raman spectrum of warfarin powder was acquired on a Renishaw Ramascope with $633 \mathrm{~nm}$ excitation $(7 \mathrm{~mW}$ ) focused via a 20x (NA 0.4) LWD objective and an acquisition time of $10 \mathrm{~s}$. To quantify relative changes in SERS signals, the peak intensity at $1322 \mathrm{~cm}^{-1}$ was subtracted from the spectral baseline intensity at $1800 \mathrm{~cm}^{-1}$ and the result normalised by dividing by the intensity of the correction standard ethanol signal at $1276 \mathrm{~cm}^{-1}\left( \pm 2 \mathrm{~cm}^{-1}\right)$, acquired under identical conditions. This was found to produce better results than peak area analysis.

\subsection{Colloid synthesis}

Five different stock colloids were prepared: silver citrate NPs, spermine-capped silver NPs, poly(allylamine hydrochloride) (PAH) coated gold NPs, gold citrate NPs and PDDA-coated silver citrate NPs. Full details of each colloid synthesis are provided in the supporting information (SI).

\subsection{Warfarin standard stock solution preparation}

Stock 1: A stock standard solution of warfarin reference standard $\left(7.50 \mu \mathrm{gmL}^{-1}\right.$ or $\left.24.32 \mathrm{mM}\right)$ was prepared by dissolving $7.50 \mathrm{mg}$ standard warfarin in phosphate buffer. WRF was dissolved 
in $10 \%(\mathrm{v} / \mathrm{v}) 0.1 \mathrm{~N} \mathrm{NaOH}$ and then diluted with $0.05 \mathrm{M}$ phosphate buffer $\mathrm{pH} 6.80$ with ratio (25:75), respectively and the volume was completed to $1000 \mathrm{~mL}$ using the same solvent.

Stock 2: $20 \mathrm{ml}$ of stock 1 was transferred into a $100 \mathrm{ml}$ volumetric flask $\left(1.50 \mu \mathrm{gmL}^{-1}\right.$ or 4.86 $\mathrm{mM}$ ) and then completed to the mark with MQ water.

Standard working solution, (Stock 3): $10 \mathrm{ml}$ of stock 2 was transferred into a $100 \mathrm{~mL}$ volumetric flask (150 $\mathrm{ngmL}^{-1}$ or $\left.486 \mathrm{nM}\right)$ and then completed to the mark with MQ water.

Further details on the procedures for the analysis of warfarin tablets and measurements of spiked human plasma are provided in the Supporting Information.

\section{Results and discussion}

Figure 1 shows representative Raman spectra of warfarin powder alongside a SERS spectra acquired in solution. Table S1 in the supporting information provides assignments of the major Raman bands observed in the warfarin powder spectrum[34]. The most distinctive peak in the SERS spectrum is at $\sim 1322 \mathrm{~cm}^{-1}$, the intensity of which was found to directly depend on the concentration of warfarin added to the colloidal solution and this was applied for analytical monitoring throughout the study. The SERS spectral profile is associated with how warfarin adsorbs onto the metal NP substrate with $\delta\left(\mathrm{CH}_{3}\right)$ and $\delta\left(\mathrm{CH}_{2}\right)$ vibrations featuring in the SERS spectral region around $\sim 1322 \mathrm{~cm}^{-1}$. However, complete assignment of the observed SERS peaks will require a further theoretical study[35] which is beyond the scope of this current work. Here we first focused on the experimental optimization of the SERS detection response. 


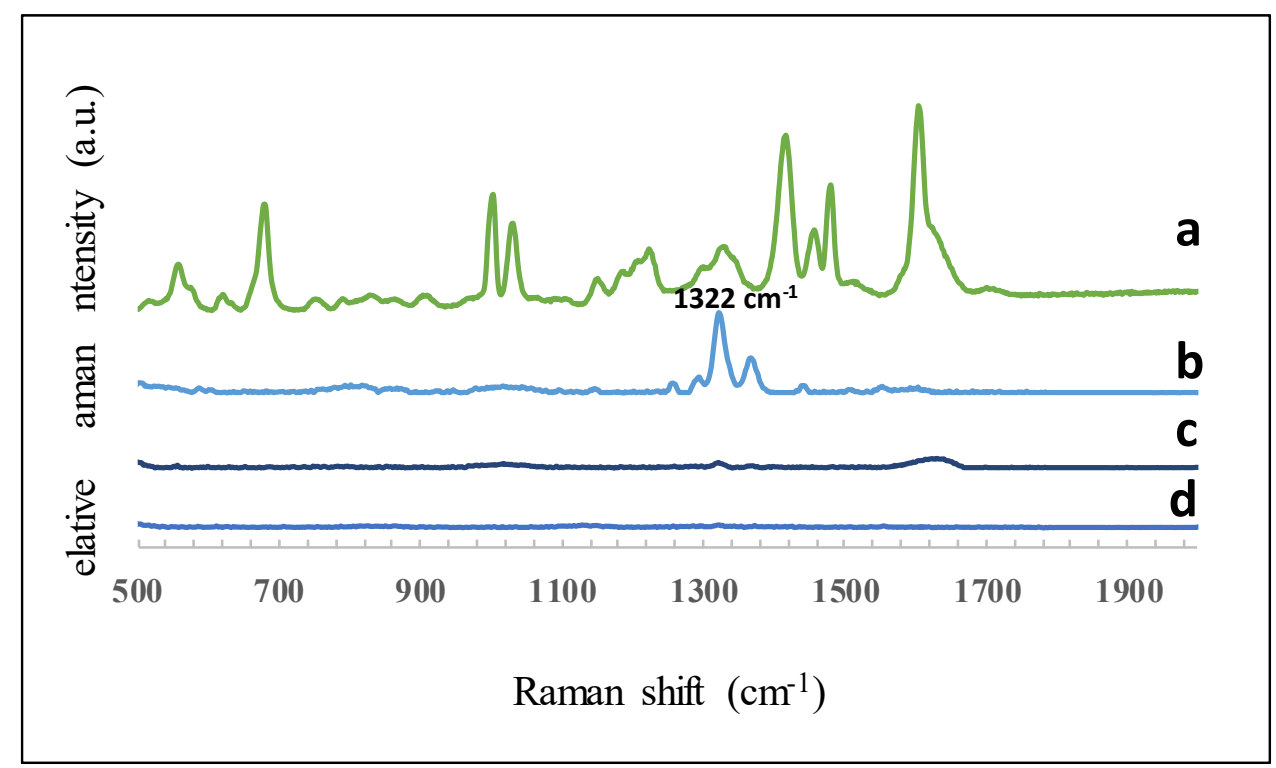

Figure 1: Raman spectra of solid warfarin (a) and (b) representative SERS spectra of warfarin standard solutions using PDDA coated Ag NPs at concentrations of $36 \mathrm{nM}$ warfarin, (c) 1.9 $\mu \mathrm{M}$ warfarin solution and (d) the colloid substrate solution only. Laser excitation at $638 \mathrm{~nm}$ and integration time $=20 \mathrm{~s}$. Spectra have been vertically offset for clarity.

\subsection{Optimization of the SERS detection method}

For the SERS detection of warfarin to be reproducible, the measurement process needs to be optimized with respect to the following parameters: (i) metal nanoparticle SERS substrate and surface functionality, (ii) time needed for the analyte to associate with the metal surface, (iii) $\mathrm{pH}$ of the media. First, the most appropriate metal surface for SERS was investigated and five different substrates were prepared: silver citrate, gold citrate, spermine capped silver nanoparticles, poly(allylamine hydrochloride) (PAH) coated gold citrate nanoparticles, and PDDA-coated silver citrate. All NP's were quasi-spherical and each colloid solution evaluated. Full details of this and all synthesis procedures are listed in the supporting information. Table S2 summarises the LSPR $\lambda_{\max }$ values and zeta-potential values while Figure S2 shows representative transmission electron microscope (TEM) images of the samples prepared with the Ag citrate stock solution from which an average particle diameter of $55.4 \pm 4.3 \mathrm{~nm}$ was obtained.

A systematic comparison of SERS spectra obtained from each of the colloidal substrates studied is shown in Figure 2. Whilst all five SERS substrates showed Raman bands from warfarin, those from PDDA-coated silver NPs were the most reproducible and had the higher signal intensity. This was determined by keeping the warfarin concentration fixed at $25 \mathrm{nM}$ 
and the particle concentrations in each measurement are also comparable. PDDA-coated silver NPs is shown to be an excellent SERS substrate for the detection of anionic warfarin since their positive zeta potentials promote electrostatic adsorption of warfarin containing negatively charged phenolic ions. The modified silver colloids can be used to detect compounds which cannot be effectively detected using traditional negatively charged citrate or hydroxylamine reduced silver nanoparticles. The SERS spectra intensities were normalized with respect to an ethanol standard under the same measurement conditions in order to establish relative intensity values.
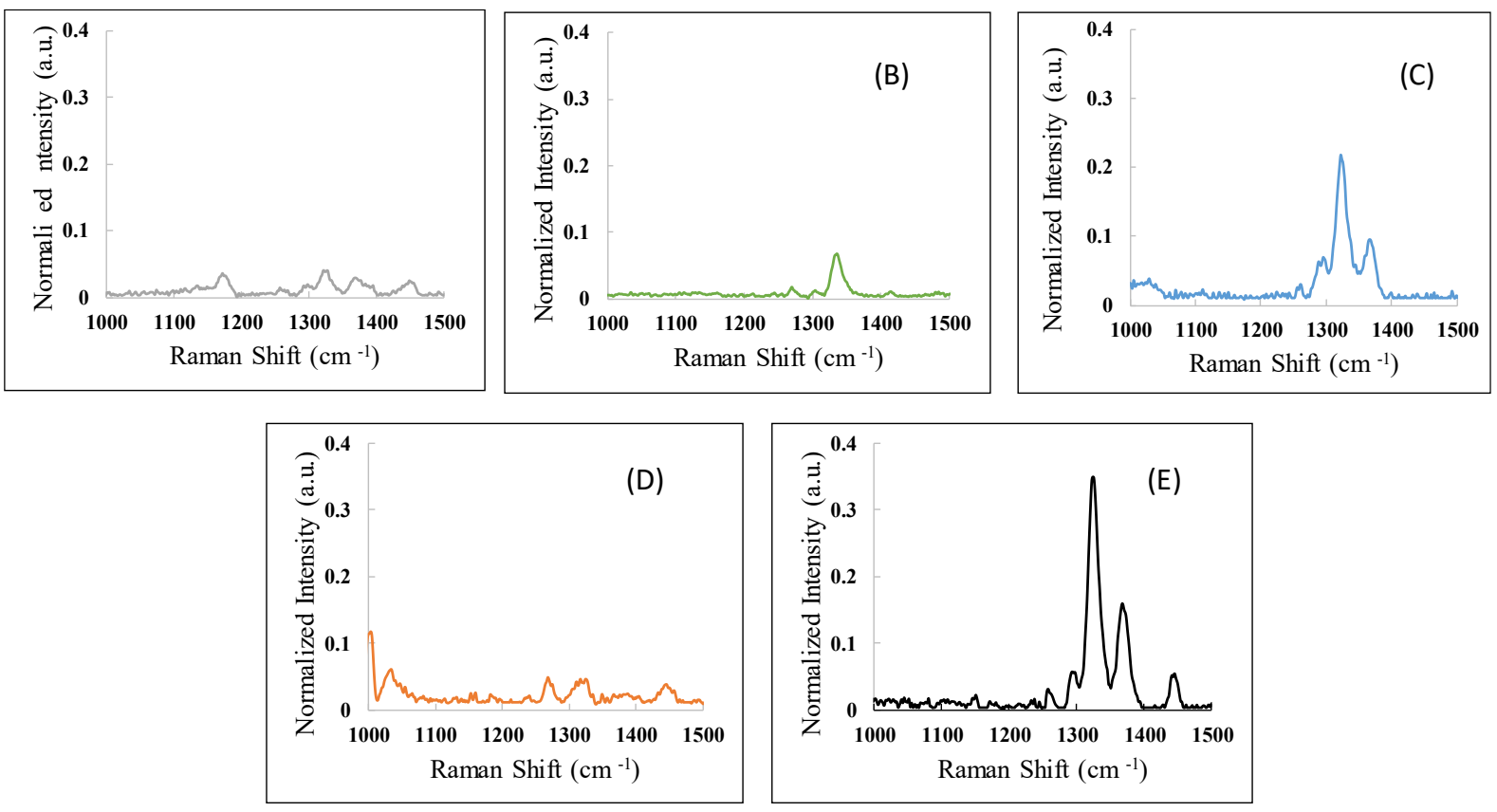

Figure 2: SERS spectra of $25 \mathrm{nM}$ warfarin detection using five different colloids: (A) silver citrate, (B) spermine-coated silver NPs, (C) PAH-coated gold nanoparticles, (D) gold citrate NPs and (E) PDDA-coated Ag NPs obtained at $638 \mathrm{~nm}$ laser excitation wavelength and normalized for comparison with respect to an EtOH solution measurement.

The SERS excitation wavelength is also an important parameter and all the data shown above were acquired at $638 \mathrm{~nm}$. Comparison measurements were performed at 532, 638 and $785 \mathrm{~nm}$ for warfarin detection using the PDDA-AgNP colloid substrate. At the same integration times and similar laser powers, the $638 \mathrm{~nm}$ excitation signal was found to be the optimal choice (see data in Fig. S3, supporting information). 
Having established the NP substrate and choice of excitation wavelength, the next optimization parameter to be investigated was the time dependence of the SERS signal upon adding warfarin to the colloidal solution. Figure 3 shows the change in the SERS signal over a period of 30 mins after $50 \mathrm{nM}$ warfarin was initially gently mixed with PDDA-AgNPs and then left under static conditions at room temperature with a spectrum acquired every $1 \mathrm{~min}$. Figure 3A shows plots of the raw SERS spectra over this time interval while Figure $3 \mathrm{~B}$ is a plot of relative intensity of the SERS peak at $1322 \mathrm{~cm}^{-1}$ minus the SERS background intensity at $1223 \mathrm{~cm}^{-1}$ versus time divided by the. This data shows that the analyte adsorbs quickly upon initial mixing with the colloid and there was no significant change in signal over the first 10 mins and then slowly decreasing at longer times. Consequently, SERS measurements were typically acquired within a minute of initial mixing the analyte and colloid.
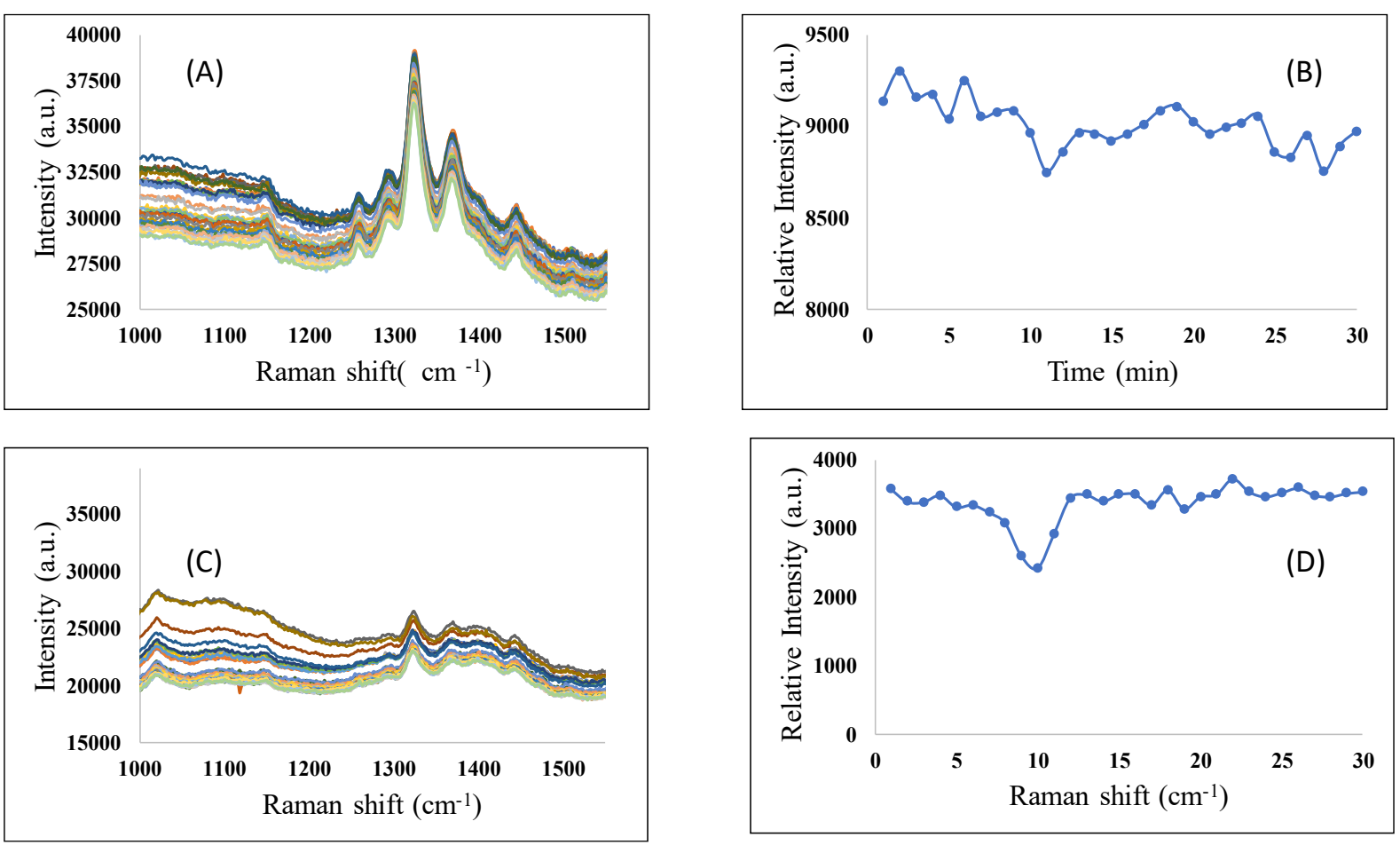

Figure 3: Monitoring time-dependent SERS signal upon addition of $50 \mathrm{nM}$ warfarin to PDDAcoated silver citrate colloid. (A) raw SERS spectra monitored at 1 min intervals; (B) plot of the relative SERS intensity of the SERS peak $\left(1322 \mathrm{~cm}^{-1}\right)$ intensity with respect to baseline intensity at $1223 \mathrm{~cm}^{-1}$. (C) SERS spectra following the introduction of an aggregating agent (10 $\mu \mathrm{L}$ of $0.5 \mathrm{M}$ sodium citrate) alongside warfarin addition, (D) corresponding relative SERS intensity change versus time. All measurements were performed at $638 \mathrm{~nm}$ excitation and an integration time of $20 \mathrm{~s}$. 
The use of aggregating agents to enhance the SERS signal is well-established [36] and different options were assessed for use with the positively charged PDDA-AgNPs. These were $\mathrm{NaCl}$, $\mathrm{KCl}, \mathrm{CaCl}_{2}, \mathrm{MgCl}_{2}$ and sodium citrate. When comparing these options, we found that citrate had the largest time-dependent effect on the SERS intensity compared to salt addition only. This is due to the stability of the colloid associated with the polyelectrolyte coating and larger polyanionic aggregating agents such as citrate are required [37]. Measurements monitoring the change in SERS signal as a function of citrate concentration is shown in Figure S5 (supporting information) and a time-dependent measurement for one of these concentrations is shown in Figure 3 (C) and (D). However, it was found that the enhancement associated with citrate induced aggregation was actually less than no use of additional aggregating agent with the relative SERS intensities increasingly lower as the amount of citrate added increased. This is because on the addition of warfarin at concentrations in low nanomolar range, partial colloid aggregation was observed. Further aggregation induced by citrate lowers the overall particle density and lowers the SERS signal obtained rather than enhancing it.

The importance of $\mathrm{pH}$ on the warfarin sensing performance was also assessed. Figure 4 shows the result of changing the $\mathrm{pH}$ of the warfarin solution prior to addition to the PDDA-AgNP colloid meaning that warfarin would be in different ionization states and consequently interact with the surface differently and affecting the SERS spectra. Monitoring of the peak intensity at $1322 \mathrm{~cm}^{-1}$ indicates a maximum intensity at a $\mathrm{pH}$ of $\sim 5.8$. It is worth noting that $\mathrm{pH} 5.8$ is the natural $\mathrm{pH}$ of the standard solution of warfarin sodium (stock 3 in the experimental procedure) when it is diluted in Milli-Q water, and that this molecule has a pKa of 5.0 which explains the drop in SERS signal when the $\mathrm{pH}>6.0$. 


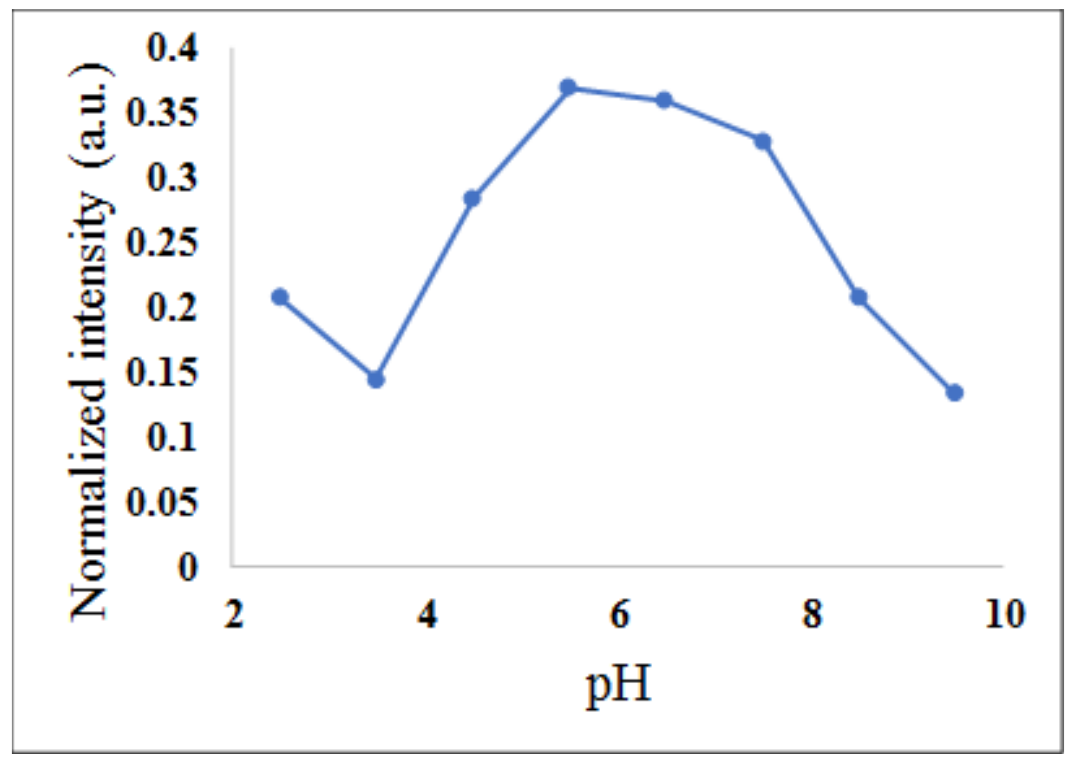

Figure 4: Effect of $\mathrm{pH}$ on SERS intensity measured in presence of $50.00 \mathrm{nM}$ warfarin added to PDDA-AgNPs. The Raman intensity was calculated across a $\mathrm{pH}$ range of $2.5-9.5$ by normalizing the $1322 \mathrm{~cm}^{-1}$ peak intensity (from which a baseline intensity at $1223 \mathrm{~cm}^{-1}$ was subtracted) with respect to a EtOH standard in each measurement.

When optimizing the SERS warfarin detection methodology, the sample volume and colloid concentration was also considered. Different volumes of PDDA-AgNP stock (100-400 $\mu \mathrm{L})$ were compared and it was found that $200 \mu \mathrm{L}$ of colloid added to $200 \mu \mathrm{L}$ of analyte volume led to the most reproducible SE S intensities, resulting in a total volume of $400 \mu \mathrm{L}$ in the measurement glass vials. In addition, the order in which the individual components were mixed was also kept constant with the drug aliquot added to the colloid. The effect of vortex mixing was compared to no shaking and gentle shaking of the glass vial after adding the warfarin solution to the colloid. It was found that the highest SERS detection intensities were obtained by gently shaking for 10 secs on mixing rather than vortexing. The effect of storage temperature was also tested. Warfarin stock solutions were stored at $4{ }^{\circ} \mathrm{C}, 25^{\circ} \mathrm{C}$ and $33^{\circ} \mathrm{C}$ and it was found that storing at $4^{\circ} \mathrm{C}$ gives the highest SERS intensity as shown in figure S6 (supporting information). The proposed SERS method is described in detail in the supporting information and the results summarised in Table S6.

\subsection{Validation of the method}

After optimising the SERS detection methodology, the validity of this approach was tested for linearity, specificity, accuracy and precision, with a series of calibration measurements for warfarin determination in pure form, and also in spiked human plasma. Various parameters 
including: linearity, limit of detection (LOD), precision, accuracy, robustness and specificity, were assessed according to ICH guidelines[38] . The calibration procedures are described in the supporting information.

An initial set of SERS calibration measurements were performed using solutions of pure warfarin. The results are shown in Figure 5(a) and (b) highlighting that the relative Raman intensities increased with greater concentration of warfarin displaying a linear relationship obtained for a concentration range of 12.0-36.0 $\mathrm{nM}\left(3.7-11.1 \mathrm{ngmL}^{-1}\right)$ in pure form. At concentrations higher than $36 \mathrm{nM}$, the SERS response subsequently decreased as shown in Figure S7. This is associated with the higher fractional surface coverage of warfarin and associated aggregation behaviour of the colloid at higher analyte concentrations defining the linear response range.

Warfarin interacts with plasma proteins via non-electrostatic interactions [39]. A repeat set of calibration measurements were then performed with warfarin in spiked human plasma. This involved spiking plasma with warfarin aliquots at different concentrations prior to an ultrafiltration step utilizing a $10 \mathrm{kDa}$ MW cut-off filter [40], which was necessary to achieve a successful SERS measurement by removing plasma components (proteins, lipids etc) that can potentially block the Ag substrate surface and impede warfarin detection. The corresponding calibration curve for warfarin detection in spiked plasma is shown in Figure 5(c), which shows a linear relationship between 12.0-25.0 $\mathrm{nM}$ (3.7-7.7 $\mathrm{ngmL}^{-1}$ ) with good recovery, reproducibility and reliability. 

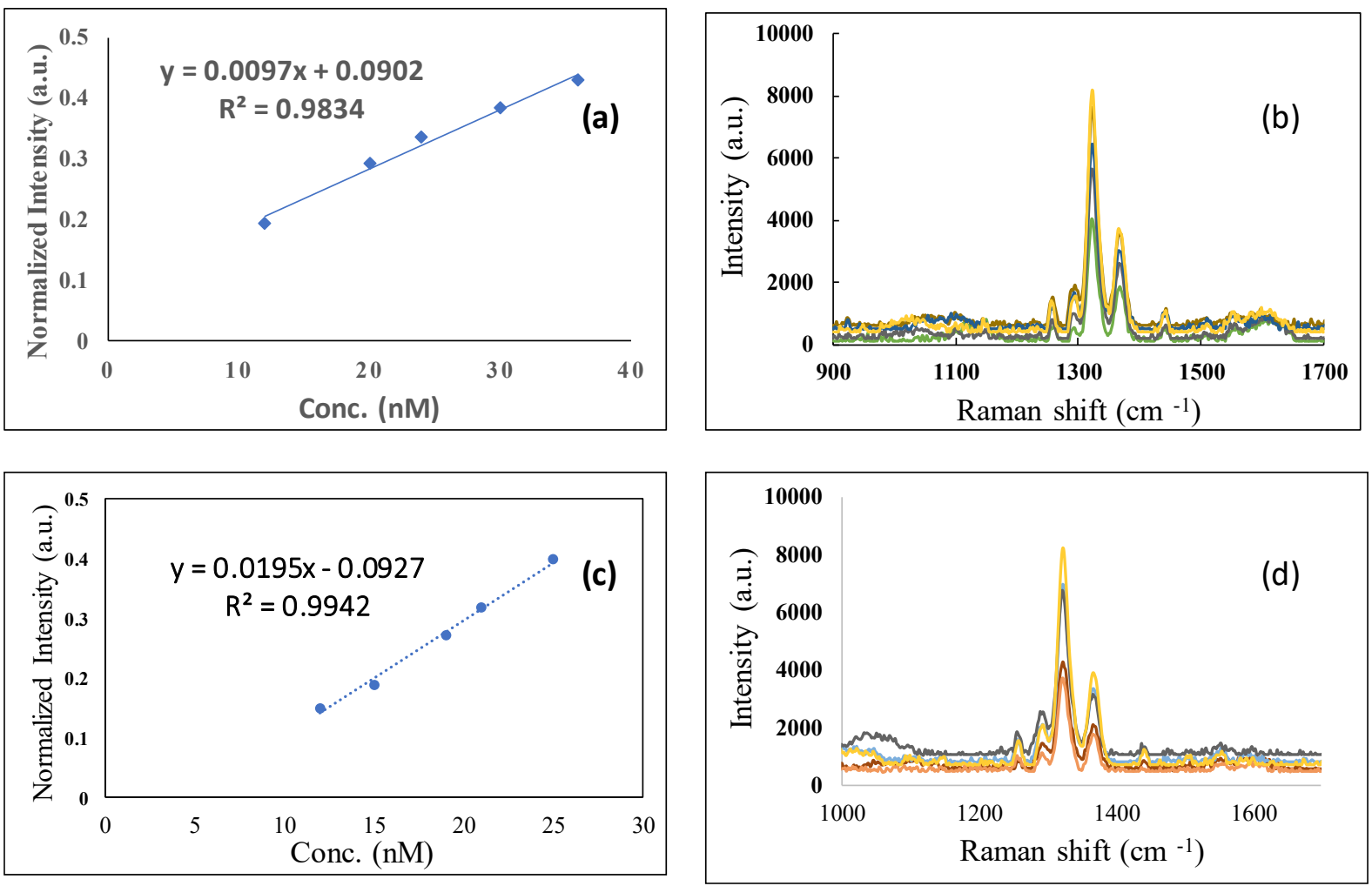

Figure 5: Calibration plots of normalized SERS intensity at $1322 \mathrm{~cm}^{-1}$ versus concentration for (a) pure warfarin solutions and (c) warfarin spiked human plasma. The corresponding background corrected SERS spectra are shown in (b) and (d) for warfarin only and spiked plasma, respectively. Measurements were performed using PDDA-AgNPs as a substrate at 638 $\mathrm{nm}$ excitation, $15 \mathrm{~mW}$ laser power and $20 \mathrm{~s}$ acquisition time.

A summary of the analysis of both sets of calibration measurements are listed in Table S3 (supporting information). The limit of detection (LOD) values were found to be 0.56 and 0.25 $\mathrm{nM}$ for warfarin in pure form and in spiked human plasma, respectively. While the limit of quantitation (LOQ) values were found to be to be 1.70 and $0.77 \mu \mathrm{gmL}^{-1}$, respectively. The LOD for warfarin in spiked plasma was lower than that in water and this may be due a variety of factors such as colloid aggregation, warfarin solvation and surface adsorption affinity onto the PDDA-coated silver surface being different in the plasma solution. The lower LOD in plasma also indicates that the filter processing step prior to spectral analysis to reduce potential nonspecific interference is effective.

The detection performance of the SERS method compares favourably with previous literature reports. The linear response range shown in figure 5 is typical of colloidal SERS sensors reported for other analytes [29,30,41-45]. The measurement dynamic range depends on a number of factors including the colloid concentration, it's aggregation behaviour and affinity 
of warfarin for the colloid surface, which can make a direct comparison with other analytes and detection systems more difficult to interpret. Non-SERS techniques recently described for warfarin detection in body fluids that have been recently reported include an electrochemical method [46] with a LOD of $1.0 \mathrm{nM}$ and a capillary electrophoresis approach [47] with a reported LOD of $0.25 \mathrm{nM}$.

The accuracy of the SERS detection method was checked by comparing directly with the official reversed-phase official HPLC method on spherical nitrile silica gel column using glacial acetic acid : ACN and water in the ratio of 12:57:53, v/v/v, respectively, at $260 \mathrm{~nm}$ [48]. As shown in Table S4, a statistical comparison of the results obtained by SERS and HPLC showed that parameters such as student's t-test and variance ratio F-test revealed no significant difference between the two methods regarding accuracy and precision. Noticeably, the SERS results have a slightly higher standard deviation and RSD than HPLC. However, the reduction in acquisition times for SERS analysis, compared to other analytical techniques such as HPLC largely compensates this. Evaluation of the intra-day precision of the SERS analysis was achieved by six replicate determination of $25.00 \mathrm{nM}$ of warfarin in its pure form, as shown in Table S5. Evaluation of the inter-day precision of the SERS method was assessed by analysing six replicates of $25.00 \mathrm{nM}$ warfarin, as shown in Table S5 over three successive days. The relative standard deviations of 2.77 were found to be small indicating good repeatability and precision.

\section{Application of SERS warfarin detection in pharmaceutical dosage form and in spiked}

plasma. In a final set of measurements, the suitability of the SERS method for the detection of warfarin in its pharmaceutical dosage form (Marevan ${ }^{\circledR} 5 \mathrm{mg}$ warfarin /tablet) and spiked human plasma was investigated. It was found that warfarin could be successfully detected with high precision and that the RSDs were found to be very small, indicating reasonable repeatability and intermediate precision of the proposed method. These results highlight that the method is highly specific as it was not affected by the presence of either excipients and preservatives commonly present in tablet formulations for measurements performed in pure form or complex components found in spiked plasma.

\section{Conclusion}


In this article, the application of SERS for the direct detection of warfarin in human plasma was successfully demonstrated. While SERS is an attractive technique for drug monitoring in biological samples due to its sensitivity and molecular specificity, its application for quantitative analysis in complex matrices such as human plasma is challenging [49]. This is due to the non-specific adsorption of plasma components (and other components used in pharmaceutical tablet formulation) potentially interfering with target adsorption sites on the surface of metal colloid substrates used in these types of measurements. The work performed here highlights the number of parameter acquisition and substrate optimization factors that need to be considered in order to optimise the SERS detection performance. A plasma cleanup step was also required in order to translate the results of the optimization study performed in buffer and apply in plasma. Compared to HPLC, the SERS approach is an attractive alternative technique that could be used in clinical settings due to low analysis cost and the emergence of hand-held Raman spectrometers as well as not requiring the use of organic solvents and lower reagent costs. Further work on the use of alternative silver and gold colloid configurations and surface chemistries is expected to lead to further improvements in sensitivity and reproducibility.

\section{Declaration of interests}

The authors declare that they have no known competing financial interests or personal relationships that could have appeared to influence the work reported in this paper.

\section{Acknowledgements}

This work has been supported by funding from MOHE-CASM, Ministry of Higher Education and Scientific Research, Egypt. 


\section{References:}

(1) Hirsh, J.; Dalen, J. E.; Anderson, D. R.; Poller, L.; Bussey, H.; Ansell, J.; Deykin, D. Oral anticoagulants: mechanism of action, clinical effectiveness, and optimal therapeutic range. Chest, 2001, 119, 8S-21S.

(2) Singer, D. E.; Albers, G. W.; Dalen, J. E.; Fang, M. C.; Go, A. S.; Halperin, J. L.; Lip, G. Y.; Manning, W. J. Antithrombotic therapy in atrial fibrillation: American College of Chest Physicians evidence-based clinical practice guidelines. Chest, 2008, 133, 546S-592S.

(3) Jacobs, L.; Cefalu, C. The use of oral anticoagulants (warfarin) in older people. $J$. Am. Geriatr. Soc., 2000, 48, 224-227.

(4) An-Chang, L.; Li-Xia, Z.; Shu-Wen, Y.; Hong-Xiang, L. Pre-treatment with puerarin affects pharmacokinetics of warfarin, but not clopidogrel, in experimental rats. Chin. J. Nat. Med., 2015, 13, 257-263.

(5) Sun, S.; Wang, M.; Su, L.; Li, J.; Li, H.; Gu, D. Study on warfarin plasma concentration and its correlation with international normalized ratio. J. Pharm. Biomed. Anal., 2006, $42,218-222$.

(6) De, D. O.; Gagliardi, L.; Turchetto, L.; Tonelli, D. HPLC determination of warfarin acenocoumarol in raw materials and pharmaceuticals. J. Pharm. Biomed. Anal., 1998, 17, 891-895.

(7) Lombardi, R.; Chantarangkul, V.; Cattaneo, M.; Tripodi, A. Measurement of warfarin in plasma by high performance liquid chromatography (HPLC) and its correlation with the international normalized ratio. Thromb. Res., 2003, 111, 281-284.

(8) Malakova, J.; Pavek, P.; Svecova, L.; Jokesova, I.; Zivny, P.; Palicka, V. New highperformance liquid chromatography method for the determination of (R)-warfarin and (S)-warfarin using chiral separation on a glycopeptide-based stationary phase. J. Chromatogr. B, 2009, 877, 32263230 .

(9) Vasquez, J. M.; Vu, A.; Schultz, J. S.; Vullev, V. I. Fluorescence enhancement of warfarin induced by interaction with $\beta$-cyclodextrin. Biotechnol. Progr., 2009, 25, 906-914.

(10) Radwan, M. A.; Bawazeer, G. A.; Aloudah, N. M.; AlQuadeib, B. T.; Aboul-Enein, H. Y. Determination of free and total warfarin concentrations in plasma using UPLC MS/MS and its application to a patient samples. Biomed. Chromatogr., 2012, 26, 6-11.

(11) Coe, R. A.; Rathe, J. O.; Lee, J. W. Supercritical fluid chromatography-tandem mass spectrometry for fast bioanalysis of R/S-warfarin in human plasma. J. Pharm. Biomed. Anal., 2006, $42,573-580$.

(12) Tanaka, Y.; Kishimoto, Y.; Terabe, S. Separation of acidic enantiomers by capillary electrophoresis-mass spectrometry employing a partial filling technique. J. Chromatogr. A, 1998, 802, 83-88.

(13) Gholivand, M.-B.; Solgi, M. Simultaneous electrochemical sensing of warfarin and maycophenolic acid in biological samples. Anal. Chim. Acta, 2018, 1034, 46-55. 
(14) De Jesus Guedes, T.; Pio dos Santos, W. T. Fast and Simple Electrochemical Analysis Kit for Quality Control of Narrow Therapeutic Index Drugs. Electroanalysis, 2018, 30, 1740-1749.

(15) Schlücker, S. Surface-Enhanced raman spectroscopy: Concepts and chemical applications. Angew. Chem. Int. Ed., 2014, 53, 4756-4795.

(16) Haynes, C. L.; McFarland, A. D.; Van Duyne, R. P. Surface-enhanced Raman spectroscopy. ACS Publications, 2005, 77, 338-346.

(17) Cotton, T. M.; Kim, J. H.; Chumanov, G. D. Application of surface-enhanced Raman spectroscopy to biological systems. J. Raman Spectrosc., 1991, 22, 729-742.

(18) Procházka, M.: Surface-Enhanced Raman Spectroscopy: Bioanalytical, Biomolecular and Medical Applications; Springer, 2015.

(19) Ellis, G.; Hendra, P. J.; Hodges, C. M.; Jawhari, T.; Jones, C. H.; Le Barazer, P.; Passingham, C.; Royaud, I.; Sánchez-Blázquez, A.; Warnes, G. M. Routine analytical Fourier transform Raman spectroscopy. Analyst, 1989, 114, 1061-1066.

(20) Fornasaro, S.; Dalla Marta, S.; Rabusin, M.; Bonifacio, A.; Sergo, V. Toward SERSbased point-of-care approaches for therapeutic drug monitoring: the case of methotrexate. Faraday Discuss., 2016, 187, 485-499.

(21) McLaughlin, C.; MacMillan, D.; McCardle, C.; Smith, W. E. Quantitative analysis of mitoxantrone by surface-enhanced resonance Raman scattering. Anal. Chem., 2002, 74, 3160-3167.

(22) Ackermann, K. R.; Henkel, T.; Popp, J. Quantitative online detection of lowconcentrated drugs via a SERS microfluidic system. Biomed. Chromatogr., 2007, 8, 2665-2670.

(23) Li, Y.-T.; Qu, L.-L.; Li, D.-W.; Song, Q.-X.; Fathi, F.; Long, Y.-T. Rapid and sensitive in-situ detection of polar antibiotics in water using a disposable Ag-graphene sensor based on electrophoretic preconcentration and surface-enhanced Raman spectroscopy. Biosens. Bioelectron., 2013, 43, 94-100.

(24) Subaihi, A.; Muhamadali, H.; Mutter, S. T.; Blanch, E.; Ellis, D. I.; Goodacre, R. Quantitative detection of codeine in human plasma using surface-enhanced Raman scattering via adaptation of the isotopic labelling principle. Analyst, 2017, 142, 1099-1105.

(25) Gracie, K.; Correa, E.; Mabbott, S.; Dougan, J. A.; Graham, D.; Goodacre, R.; Faulds, K. Simultaneous detection and quantification of three bacterial meningitis pathogens by SERS. Chem. Sci, 2014, 5, 1030-1040.

(26) Ma, K.; Yuen, J. M.; Shah, N. C.; Walsh Jr, J. T.; Glucksberg, M. R.; Van Duyne, R. P. In vivo, transcutaneous glucose sensing using surface-enhanced spatially offset Raman spectroscopy: multiple rats, improved hypoglycemic accuracy, low incident power, and continuous monitoring for greater than 17 days. Anal. Chem., 2011, 83, 9146-9152.

(27) Alharbi, O.; Xu, Y.; Goodacre, R. Detection and quantification of the opioid tramadol in urine using surface enhanced Raman scattering. Analyst, 2015, 140, 5965-5970. 
(28) Zhang, D.; Haputhanthri, R.; Ansar, S. M.; Vangala, K.; De Silva, H. I.; Sygula, A.; Saebo, S.; Pittman, C. U. Ultrasensitive detection of malondialdehyde with surface-enhanced Raman spectroscopy. Anal. Bioanal.Chem., 2010, 398, 3193-3201.

(29) Shen, W.; Lin, X.; Jiang, C.; Li, C.; Lin, H.; Huang, J.; Wang, S.; Liu, G.; Yan, X.; Zhong, Q. Reliable quantitative SERS analysis facilitated by core-shell nanoparticles with embedded internal standards. Angew. Chem. Int. Ed., 2015, 54, 7308-7312.

(30) Goodacre, R.; Graham, D.; Faulds, K. Recent developments in quantitative SERS: Moving towards absolute quantification. Trends Anal. Chem., 2018, 102, 359-368.

(31) Mishra, A.; Srivastava, S. K.; Swati, D. Study of structure-activity relationship of enantiomeric, protonated and deprotonated forms of warfarin via vibrational spectroscopy and DFT calculations. Spectrochim. Acta A Mol. Biomol. Spectrosc., 2013, 113, 439-446.

(32) Arruabarrena, J.; Coello, J.; Maspoch, S. Raman spectroscopy as a complementary tool to assess the content uniformity of dosage units in break-scored warfarin tablets. Int. J. Pharm., 2014, 465, 299-305.

(33) Kostova, I.; Amalanathan, M.; Joe, I. H. Molecular first order hyperpolarizability and vibrational spectral investigation of Warfarin sodium. Chem. Phys., 2010, 378, 88-102.

(34) Rahman, Z.; Mohammad, A.; Akhtar, S.; Siddiqui, A.; Korang-Yeboah, M.; Khan, M. A. Chemometric Model Development and Comparison of R aman and $13 \mathrm{C}$ Solid-State Nuclear Magnetic Resonance-Chemometric Methods for Quantification of Crystalline/Amorphous Warfarin Sodium Fraction in the Formulations. J. Pharm. Sci., 2015, 104, 2550-2558.

(35) Rahman, Z.; Bykadi, S.; Siddiqui, A.; Khan, M. A. Comparison of X-ray Powder Diffraction and Solid-State Nuclear Magnetic Resonance in Estimating Crystalline Fraction of Tacrolimus in Sustained-Release Amorphous Solid Dispersion and Development of Discriminating Dissolution Method. J. Pharm. Sci., 2015, 104, 1777-1786.

(36) Guerrini, L.; Graham, D. Molecularly-mediated assemblies of plasmonic nanoparticles for Surface-Enhanced Raman Spectroscopy applications. Chem. Soc. Rev., 2012, 41, 7085-7107.

(37) McLintock, A.; Hunt, N.; Wark, A. W. Controlled side-by-side assembly of gold nanorods and dye molecules into polymer-wrapped SERRS-active clusters. Chem. Commun., 2011, $47,3757-3759$.

and

(38) ICH. ICH Harmonized Tripartite Guidline, Validation of Analytical Procedures: Text

Methodology, Q2 (R1), Parent Guideline on Methodology. International Conference on Harmonization, Geneva, Switzerland, 2005, 11-12.

(39) O'Reilly, R. A. Interaction of the anticoagulant drug warfarin and its metabolites with human plasma albumin. J. Clin. Invest., 1969, 48, 193-202.

(40) Bonnier, F.; Blasco, H.; Wasselet, C.; Brachet, G.; Respaud, R.; Carvalho, L. F. C.; Bertrand, D.; Baker, M. J.; Byrne, H. J.; Chourpa, I. Ultra-filtration of human serum for improved quantitative analysis of low molecular weight biomarkers using ATR-IR spectroscopy. Analyst, 2017, $142,1285-1298$. 
(41) Cheng, J.; Su, X.-O.; Wang, S.; Zhao, Y. Highly sensitive detection of clenbuterol in animal urine using immunomagnetic bead treatment and surface-enhanced Raman spectroscopy. Sci. Rep., 2016, 6, 32637.

(42) Gracie, K.; Correa, E.; Mabbott, S.; Dougan, J. A.; Graham, D.; Goodacre, R.; Faulds, K. Simultaneous detection and quantification of three bacterial meningitis pathogens by SERS. Chem. Sci., 2014, 5, 1030-1040.

(43) Yuen, C.; Zheng, W.; Huang, Z. Low-level detection of anti-cancer drug in blood plasma using microwave-treated gold-polystyrene beads as surface-enhanced Raman scattering substrates. Biosens Bioelectron, 2010, 26, 580-584.

(44) Teng, Y.; Liu, W.; Liu, J.; Nie, Y.; Li, P.; He, C. Surface-enhanced raman scattering sensing of trace fenthion coupled with stable silver colloids and oh stretching band of water as an internal standard. J. Anal. Chem., 2016, 71, 891-895.

(45) Graham, D.; Stevenson, R.; Thompson, D. G.; Barrett, L.; Dalton, C.; Faulds, K. Combining functionalised nanoparticles and SERS for the detection of DNA relating to disease. Faraday discuss., 2011, 149, 291-299.

(46) Yawari, I.; Kaykhaii, M. Determination of (S)-warfarin using an activated screen printed gold electrode modified with gold nanoparticles and an enantioselective molecularly imprinted polymer. Anal. Methods, 2017, 9, 6583-6589.

(47) Chang, Y.-T.; Wang, Z.-R.; Hsieh, M.-M. Sensitive determination of warfarin and its metabolic enantiomers in body fluids via capillary electrophoresis combined with ultrasound-assisted dispersive liquid-liquid microextraction and online sample stacking. Microchem. J., 2019.

(48) BP. The British Pharmacopoeia, $2019^{\text {th }}$ Edn.; Her majestys Stationery Office, Vallender M.; London. 2019.

(49) Dong, O.; Lam, D. C. Silver nanoparticles as surface-enhanced Raman substrate for quantitative identification of label-free proteins. Mater. Chem. Phys., 2011, 126, 91-96. 


\section{Supporting Information for}

\section{Detection and quantification of warfarin in pharmaceutical dosage form and in spiked human plasma using surface enhanced Raman scattering}

Maha A. Sultan ${ }^{\mathrm{a}}$, Maha M. Abou El-Alamin ${ }^{\mathrm{a}}$, Alastair W. Wark ${ }^{\mathrm{b}}$ and Marwa M. Azab*a,b

a Analytical Chemistry Department, Faculty of Pharmacy, Helwan University, 11795, Cairo, Egypt

${ }^{b}$ Centre for Molecular Nanometrology, Dept. of Pure \& Applied Chemistry, Technology and Innovation Centre, 99 George St., University of Strathclyde, Glasgow, G1 1RD, UK.

Preparation of all the colloids used during the optimization investigation are listed here plus additional supportive data (Figures S1-S7, Tables S1-S6). 


\section{$\underline{\text { Experimental details }}$}

\section{Preparation of silver citrate NPs}

Silver citrate nanoparticles were prepared according to the procedure described by Lee and Meisel [1]. $90.00 \mathrm{mg}$ of silver nitrate was dissolved in a $1000 \mathrm{~mL}$ Erlenmeyer flask filled with $500 \mathrm{ml}$ of Milli-Q water with a thermometer inside the flask. The solution was heated to boiling under reflux and then $10 \mathrm{~mL}$ of freshly prepared sodium citrate aqueous solution $(1 \%$ $\mathrm{w} / \mathrm{v}$ ) was added quickly under vigorous stirring. After sodium citrate addition, the colour changes to yellow, and then finally grey. The mixture was kept boiling under reflux and stirring for $90 \mathrm{~min}$ and then slowly cooled down to room temperature [2].

The colloid was then analysed by UV-vis spectroscopy, and the $\lambda_{\max }$ obtained was $407 \mathrm{~nm}$. Using the Beer-Lambert Law and a molar extinction coefficient of $1.81 \times 10^{10}$ the stock solution was diluted to get the bulk concentration of $0.055 \mathrm{nM}$ (O.D. $\sim 1$ at LSPR $\lambda_{\max }$ ). The final concentration of nanoparticles in the samples under analysis was calculated to be 27.50 pM. The nanoparticle size was estimated using dynamic light scattering (DLS). The approximate sizes of the silver citrate nanoparticles used in this work were determined to be $55.40 \pm$ $4.30 \mathrm{~nm}$ from TEM measurements. All experiments were performed under ambient conditions without degassing.

\section{Preparation of spermine capped silver nanoparticles}

$20 \mu \mathrm{L}$ of $0.5 \mathrm{M}$ silver nitrate was added to $10 \mathrm{~mL}$ Milli-Q water. Next, $7 \mu \mathrm{L}$ of $0.1 \mathrm{M}$ spermine hydrochloride was added to the silver nitrate solution. Subsequently, under vigorous stirring, $250 \mu \mathrm{L}$ of $0.01 \mathrm{M} \mathrm{NaBH}_{4}$ was quickly added to the solution and then more gently stirred for a further $20 \mathrm{~min}$ [3]. Particle formation was immediately observed as the colour turned yellow. Formation of the particles was verified by UV-visible spectroscopy obtaining a $\lambda_{\max }$ of $407 \mathrm{~nm}$. An extra step during glassware washing should be done for positively-charged silver nanoparticles to prevent adsorption to glassware used for the nanoparticle preparation and storage. This involved coating the glassware with polyethyleneimine (PEI) $[3,4]$. The glassware was filled with $0.2 \% \mathrm{w} / \mathrm{w}$ PEI aqueous solution and incubated for $2 \mathrm{~h}$. Afterwards, the glassware was rinsed once with Milli-Q water and dried with $\mathrm{N}_{2}$ flow. 


\section{Preparation of poly(allylamine hydrochloride) (PAH) stabilized gold nanoparticles}

$76.6 \mathrm{mg}$ of $\mathrm{HAuCl}_{4}$ was added to $380 \mathrm{ml} \mathrm{Milli-Q-water,} 36.4 \mathrm{mg} \mathrm{PAH}$ was dissolved and sonicated in $20 \mathrm{~mL} \mathrm{H} \mathrm{H}_{2} \mathrm{O}$. PAH solution was added to the gold solution and the mixture was heated to $98^{\circ} \mathrm{C}$ for $10-15$ min until the colour changed to a deep red [5].

\section{Preparation of gold citrate nanoparticles}

Gold nanospheres were prepared by a slight modification of the Turkevich method [6]. 12.0 $\mathrm{mg}$ of $\mathrm{HAuCl}_{4}$ was added to $100 \mathrm{~mL}$ Milli-Q water, heated to boiling and then reduced using $11.2 \mathrm{mg}$ of sodium citrate tribasic dihydrate in $7.5 \mathrm{~mL}$ Milli-Q water resulting in colloidal gold nanospheres with a diameter of $50 \mathrm{~nm}$.

\section{Preparation of PDDA-coated Ag nanoparticles}

$600 \mu \mathrm{l}$ of poly(diallyldimethylammonium) chloride, PDDA, (MW 100,000, $20 \mathrm{wt} \%$ ) was dissolved in $19.4 \mathrm{~mL}$ of $5 \mathrm{mM} \mathrm{NaCl}$ and added dropwise to $80 \mathrm{~mL}$ of rapidly stirring $\mathrm{Ag}$ nanoparticles in pre-coated glass vials with PEI. The mixture was stirred for a further $10 \mathrm{~min}$ and centrifuged at $6000 \mathrm{rpm}$ for $20 \mathrm{~min}$. The sample was re-suspended in $80 \mathrm{ml} \mathrm{H}_{2} \mathrm{O}$. Aliquots of freshly prepared PDDA-AgNPs should be stored in PEI coated glass vials.

\section{Standard stock solutions}

Stock 1: A stock standard solution of warfarin reference standard ( $7.5 \mu \mathrm{gmL}^{-1}$ or $\left.24.32 \mathrm{mM}\right)$ was prepared by dissolving $7.5 \mathrm{mg}$ standard warfarin in phosphate buffer. To dissolve the warfarin, $10 \%(\mathrm{v} / \mathrm{v}) 0.1 \mathrm{~N} \mathrm{NaOH}$ was used and then diluted with $0.05 \mathrm{M}$ phosphate buffer $\mathrm{pH}$ 6.8 with ratio (25:75), respectively and the volume was completed to $1000 \mathrm{ml}$ using the same solvent.

Stock 2: $20 \mathrm{~mL}$ of stock 1 solution was transferred into a $100 \mathrm{~mL}$ volumetric flask $(1.5$ $\mu \mathrm{g} / \mathrm{mL}$ or $4.86 \mathrm{mM}$ ) and then filled with Milli-Q water.

Stock 3: $10 \mathrm{~mL}$ of stock 2 solution was transferred into a $100 \mathrm{~mL}$ volumetric flask (150 $\mathrm{ng} / \mathrm{mL}$ or $486 \mathrm{nM}$ ) and then filled with Milli-Q water.

\section{Calibration graph construction for pure warfarin powder}

All dilution factors were taken into account when predicting final warfarin concentrations. $200 \mu \mathrm{L}$ of warfarin solution from stock $\mathrm{C}$ at variable concentrations were added to $200 \mu \mathrm{L}$ 
freshly prepared PDDA-AgNP colloid in a glass vial and mixed for $10 \mathrm{~s}$ and immediately analysed by a Snowy Range Instruments Sierra 2.0 spectrometer at $15 \mathrm{~mW}$ power and $20 \mathrm{~s}$ exposure time with an incident laser wavelength of $638 \mathrm{~nm}$. Spectra were baseline corrected using a multipoint polynomial fit. Each spectrum was an average of two scans. For all analyses the spectral range is 2000 to $200 \mathrm{~cm}^{-1}$ with a spectral resolution of $8 \mathrm{~cm}^{-1}$.

To quantify the SERS peak intensity and warfarin concentration, the peak intensity at $\Delta v=$ $1322 \mathrm{~cm}^{-1}$ was subtracted from the background region intensity at $1800 \mathrm{~cm}^{-1}$ and the result divided by the intensity of the correction standard ethanol signal at $1276 \mathrm{~cm}^{-1}\left( \pm 2 \mathrm{~cm}^{-1}\right)$, acquired under identical conditions. This was repeated at various drug concentrations to obtain the calibration graph and the corresponding regression equation was derived. Ethanol was used to optimise the signal collection as well as to provide an intensity reference for data normalization.

\section{Procedure for Tablet analysis}

Ten tablets were weighed and ground into a fine powder. An amount of the tablet weight equivalent to $7.5 \mathrm{mg}$ warfarin was accurately weighed, transferred to a $1000 \mathrm{ml}$ volumetric flask and dissolved in $0.05 \mathrm{M}$ phosphate buffer. After sonication for $30 \mathrm{~min}$ the volume was diluted with Milli-Q water. The produced solution $\left(7.50 \mu \mathrm{gmL}^{-1}\right.$ or $\left.24.3 \mathrm{mM}\right)$ was filtered with a $0.2 \mu \mathrm{m}$ disposable syringe filter and then diluted to obtain $\left(150 \mathrm{ngmL}^{-1}\right.$ or $\left.486 \mathrm{nM}\right)$. $200 \mu \mathrm{L}$ aliquots from this stock were added to $200 \mu \mathrm{L}$ freshly prepared PDDA-AgNP's in a glass vial and mixed thoroughly for 10 s to cover the concentration range, with the same calibration procedure as described above then performed. To quantify the SERS peak intensity and tablet warfarin concentration, the peak intensity at $\Delta v=1322 \mathrm{~cm}^{-1}$ was subtracted from the background intensity at $1800 \mathrm{~cm}^{-1}$ and the result divided by the intensity of the correction standard ethanol at $1276 \mathrm{~cm}^{-1}\left( \pm 2 \mathrm{~cm}^{-1}\right)$, acquired under identical conditions. This was repeated at various drug concentrations to obtain the calibration graph and the corresponding regression equation was derived.

\section{Procedure for detection in spiked human plasma}

$250 \mu \mathrm{L}$ of human plasma (recently thawed from storage) were transferred into a $0.5 \mathrm{~mL}$ Amicon ultrafiltration tube with a membrane of $10 \mathrm{kDa}$ porous size from Millipore 
(Darmstadt, Germany), diluted with $125 \mu \mathrm{L}$ of 120, 128, 160, 180 and $200 \mathrm{nM}$ warfarin and $125 \mu \mathrm{L}$ of Milli-Q water, then vortex mixing. Final concentrations were 30.0, 32.0, 40.0, 45.0 and $50.0 \mathrm{nM}$ warfarin. The solutions were centrifuged at $10,000 \mathrm{rpm}$ for 15 minutes. Then, $200 \mu \mathrm{L}$ of the permeated phase (aqueous solution containing warfarin) was transferred to a glass vial. $200 \mu \mathrm{L}$ aliquots from this stock were added to $200 \mu \mathrm{L}$ freshly prepared PDDAAgNP in a glass vial and mixed thoroughly for $10 \mathrm{~s}$, with the same calibration procedure as described above then performed. To quantify the SERS peak intensity and tablet warfarin concentration, the peak intensity at $\Delta v=1322 \mathrm{~cm}^{-1}$ was subtracted from the intensity at 1800 $\mathrm{cm}^{-1}$ and the result divided by the intensity of the correction standard ethanol at $1276 \mathrm{~cm}^{-1}$ $\left( \pm 2 \mathrm{~cm}^{-1}\right)$, acquired under identical conditions. This was repeated at various drug concentrations to obtain the calibration graph and the corresponding regression equation was derived.

The Amicon ultrafiltration tubes were reused for the analysis after washing. The washing procedure consisted of triple spinning with a solution of $0.1 \mathrm{M} \mathrm{NaOH}$, followed by triple rinses with Milli-Q water. For both washing and rinsing, $0.5 \mathrm{~mL}$ of the washing liquid was added to the filters and centrifuged for $10 \mathrm{~min}$ at $10000 \mathrm{rpm}$ followed by upside down spinning at $1000 \mathrm{rpm}$ for $2 \mathrm{~min}$ in order to remove any residual solution stuck in the filter [7]. 


\section{Additional data}

The pure warfarin powder Raman spectrum is shown in Figure 1a in the main article alongside an example SERS spectrum (Fig. 1b).

Table S1: Distinct Raman peak assignments for warfarin powder (Figure 1a in manuscript) [8],[9].

\begin{tabular}{|l|l|}
\hline Raman shift $\left(\mathbf{c m}^{-\mathbf{1}}\right)$ & Raman peak assignment \\
\hline 682 & $v(\mathrm{CC})$ \\
\hline 817 & $v(\mathrm{COC})$ \\
\hline 1001,1034 & $v(\mathrm{CC})$ Aromatic rings \\
\hline 1338 & $\delta\left(\mathrm{CH}_{3}\right)$ \\
\hline 1420 & $\delta\left(\mathrm{CH}_{2}\right)$ \\
\hline 1483 & $v\left(\mathrm{CH}_{3}\right)$ \\
\hline 1608 & $v(\mathrm{C}=\mathrm{C})$ \\
\hline 1709 & $v(\mathrm{C}=\mathrm{O})$ \\
\hline
\end{tabular}

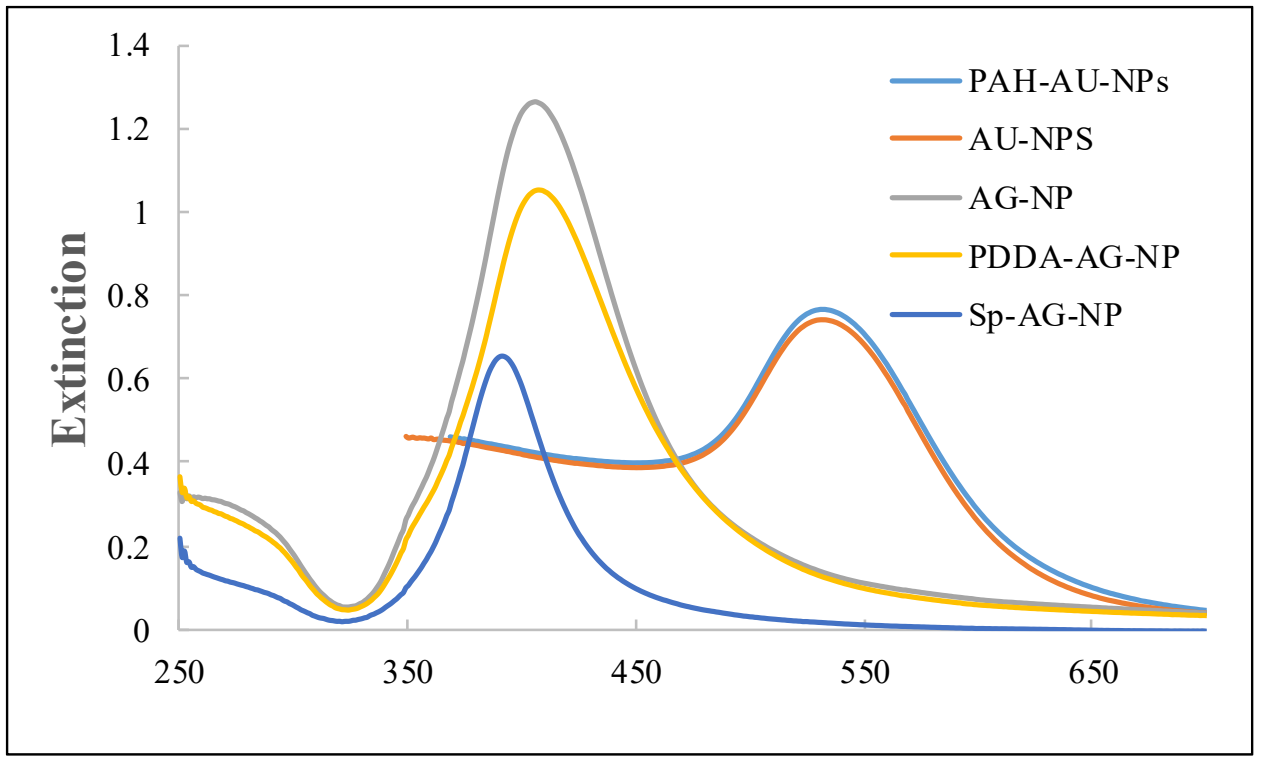

Figure S1: Extinction profiles of the five different colloids prepared. 
Table S2. Summary of LSPR $\lambda_{\max }$ and zeta potential measurements obtained for the colloids used in this study.

\begin{tabular}{|l|c|c|}
\hline Colloid & $\lambda_{\max }(\mathbf{n m})$ & Zeta potential \\
\hline Citrate stabilized silver nanoparticles & 406 & $-35.8 \pm 2.9$ \\
\hline spermine capped silver nanoparticles & 391 & $+28.8 \pm 2.3$ \\
\hline PAH-coated gold nanoparticles & 533 & $+33.7 \pm 2.6$ \\
\hline Citrate stabilized gold nanoparticles & 531 & $-29.6 \pm 2.1$ \\
\hline PDDA-coated silver nanoparticles & 407 & $+50.1 \pm 4.2$ \\
\hline
\end{tabular}



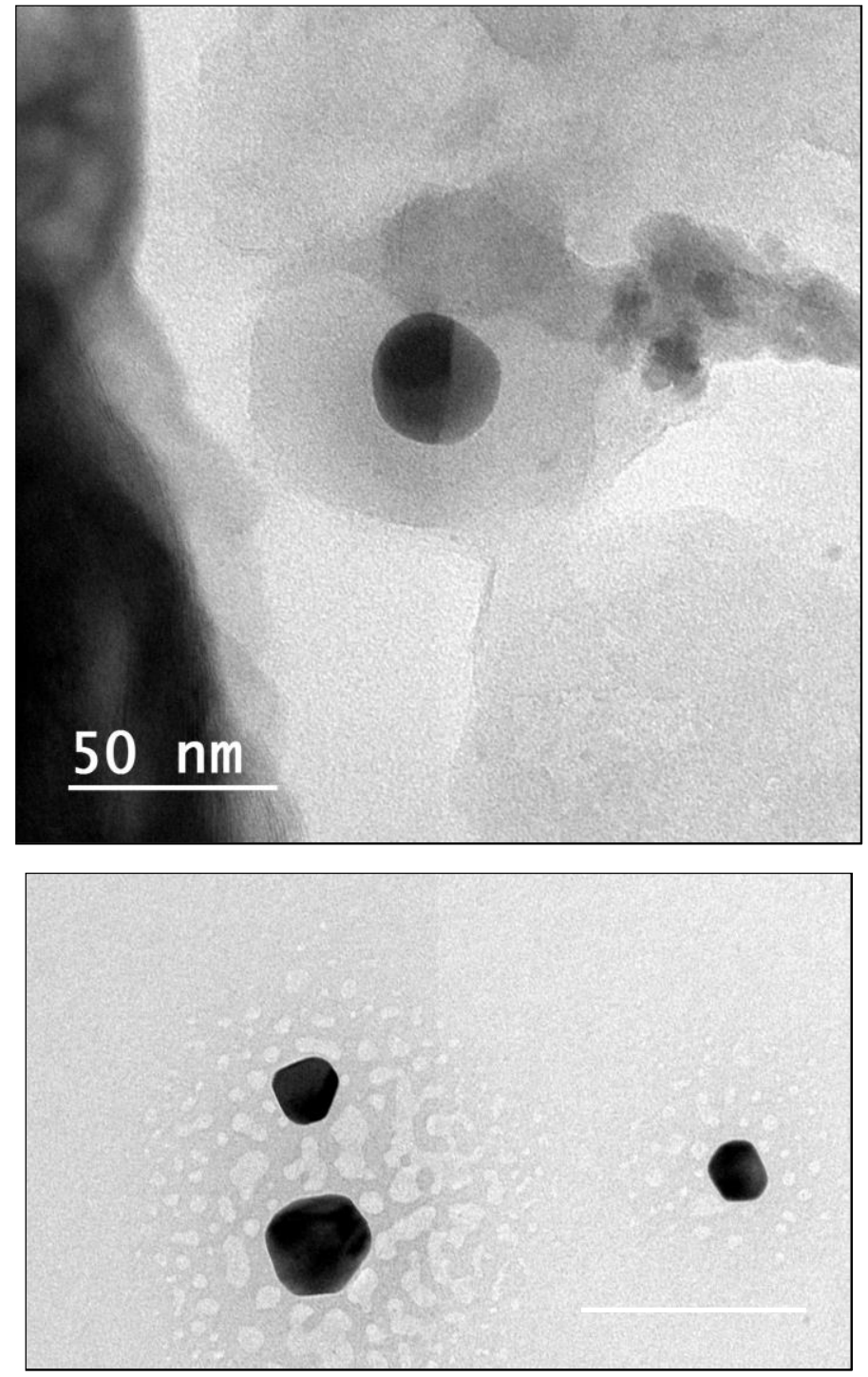

Figure S2: Representative TEM images of PDDA-coated silver citrate colloid, scale bar $=50 \mathrm{~nm}$ in both images. 


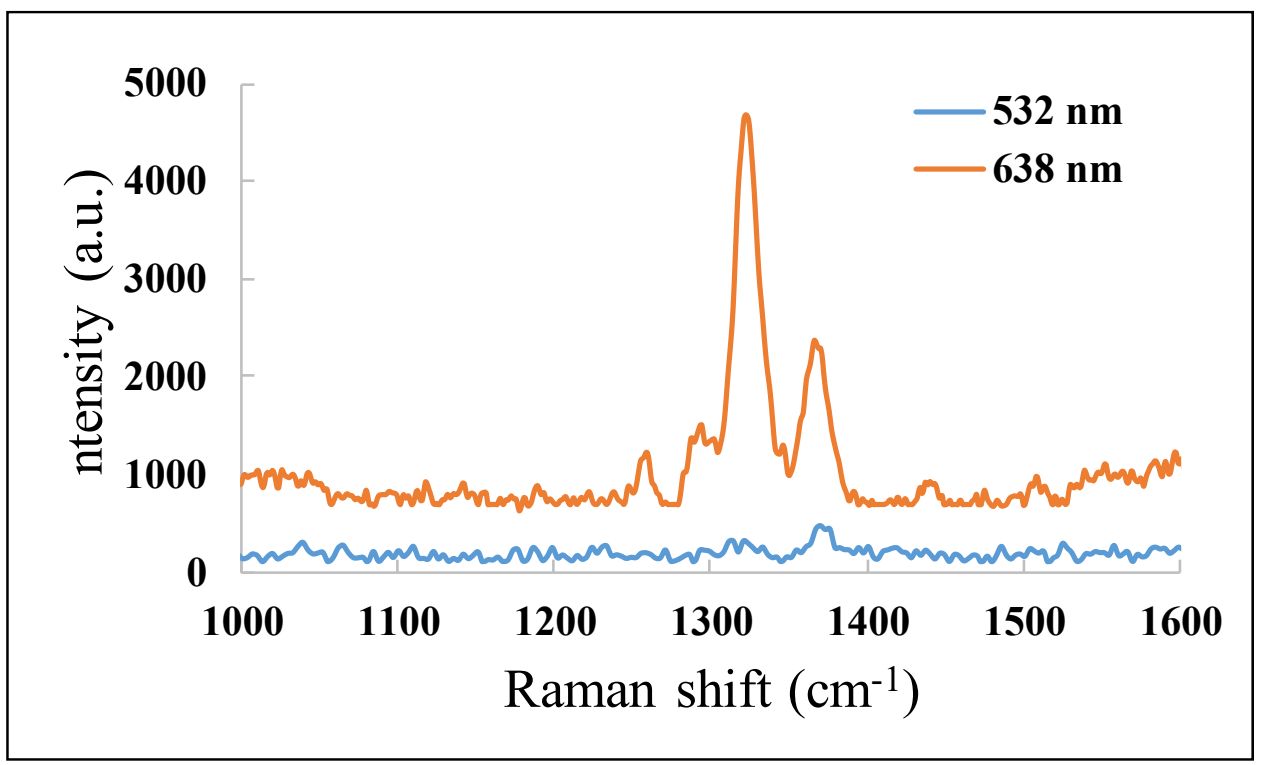

Figure S3: SERS analysis of $20 \mathrm{nM}$ warfarin using PDDA-Ag citrate as a substrate with $\lambda_{\max }=407 \mathrm{~nm}$ obtained at different excitation wavelengths. The integration times are the same in both measurements at 20s and using the maximum available laser power $15 \mathrm{~mW}$ for $532 \mathrm{~nm}$ and $638 \mathrm{~nm}$. Spectra has been baseline corrected and offset for comparison. No spectral features in this spectral region were observed at $785 \mathrm{~nm}$ excitation and similar powers (data not shown) resulting in the selection of $638 \mathrm{~nm}$ excitation for all subsequent measurements.
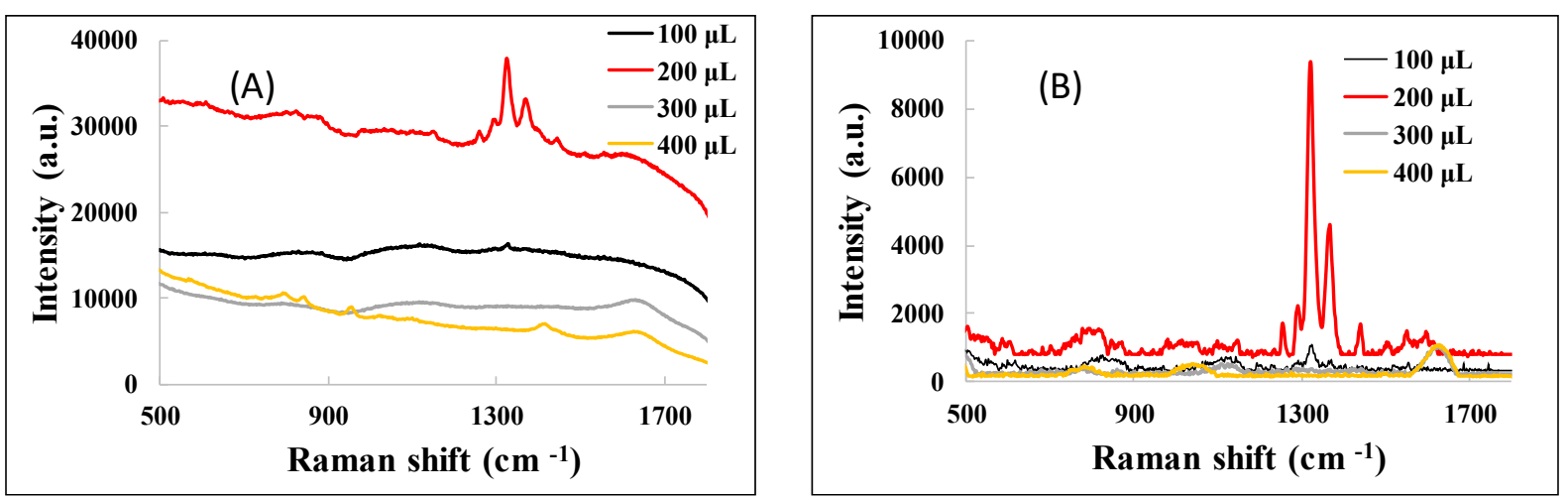

Figure S4: (A) Raw SERS spectra of $35 \mathrm{nM}$ warfarin solution mixed with PDDA-Ag citrate colloid at different added warfarin volumes $(100-400 \mu \mathrm{L})$ obtained at $638 \mathrm{~nm}$ laser excitation wavelength; (B) shows the corresponding background corrected SERS spectra. 

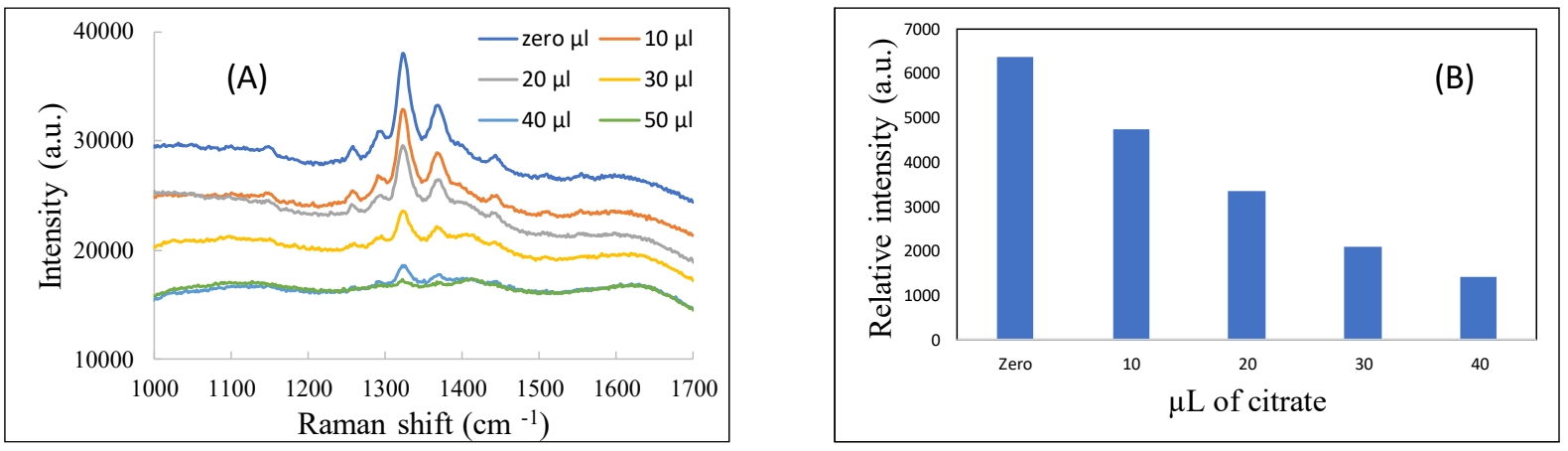

Figure S5: Time-dependent monitoring of SERS signal changes upon addition of different volumes ( 10 to $40 \mu \mathrm{L}$ ) of $0.5 \mathrm{M}$ sodium citrate aggregating agent to a $200 \mu \mathrm{L}$ PDDA-AgNP solution mixed with $25 \mathrm{nM}$ warfarin. (A) Raw SERS spectra and (B) plot of the relative SERS intensity of the peak at $1322 \mathrm{~cm}^{-1}$ from which the baseline intensity at $1223 \mathrm{~cm}^{-1}$ is subtracted. Measurements were acquired within 1 min after mixing.

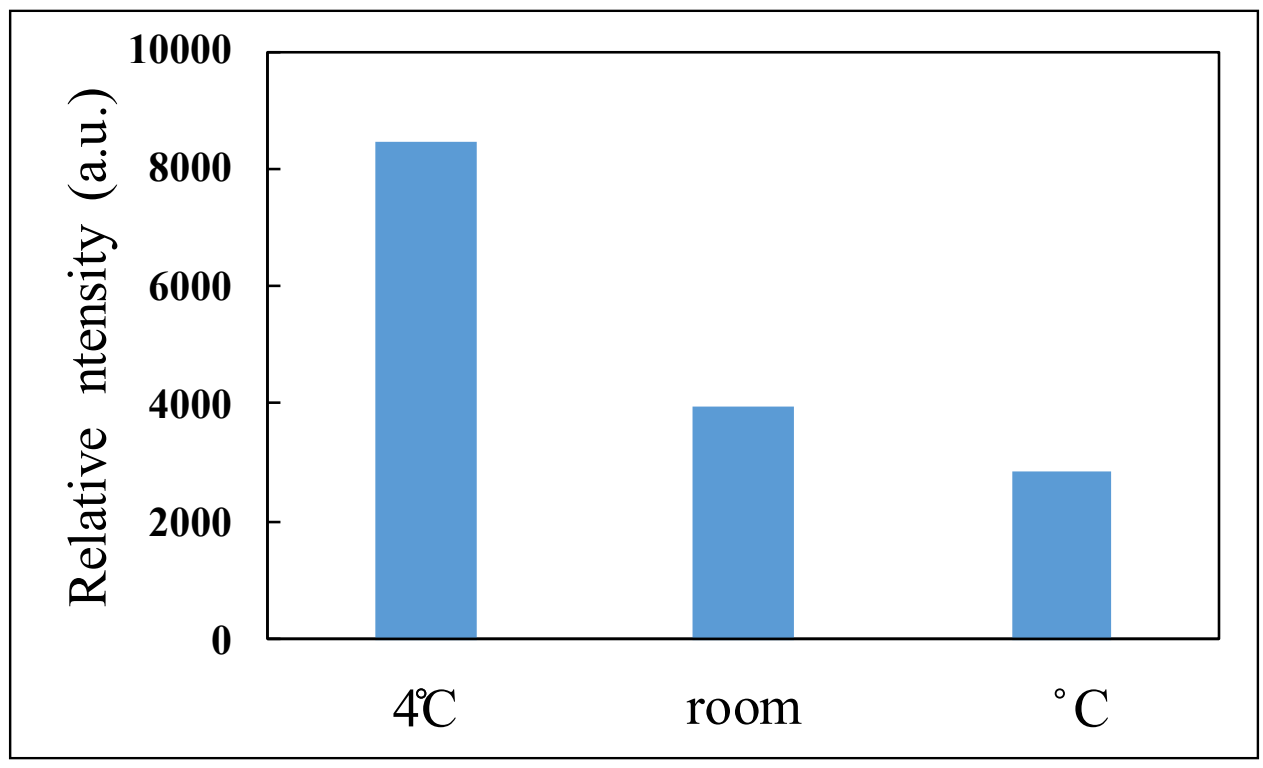

Figure S6: The effect of storage temperature of warfarin aliquots was tested on $25 \mathrm{nM}$ warfarin. The warfarin stock solution was stored at $4^{\circ} \mathrm{C}, 25^{\circ} \mathrm{C}$ and $33^{\circ} \mathrm{C}$ for 24 hours and it was found that storing warfarin aliquots at $4{ }^{\circ} \mathrm{C}$ gave the highest SERS intensity. 


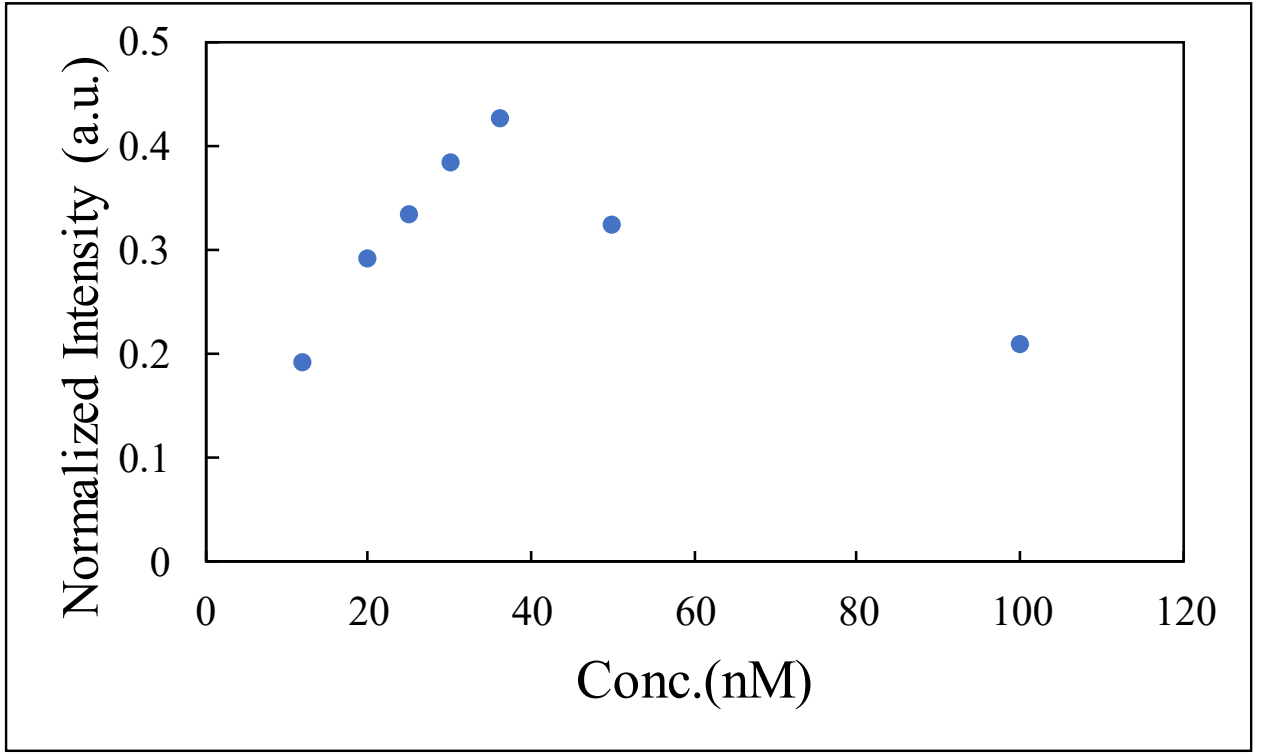

Figure S7: Extended plot of calibration curve monitoring SERS intensity for the detection of pure warfarin in pure form at concentrations $12.0-110.0 \mathrm{nM}$ $\left(3.70-33.88 \mathrm{ngmL}^{-1}\right)$. This shows that the linear response range is confined to between $12.0-36.0 \mathrm{nM}$. All measurements obtained at a laser excitation wavelength of $638 \mathrm{~nm}, 15 \mathrm{~mW}$ and $20 \mathrm{~s}$ acquisition time.

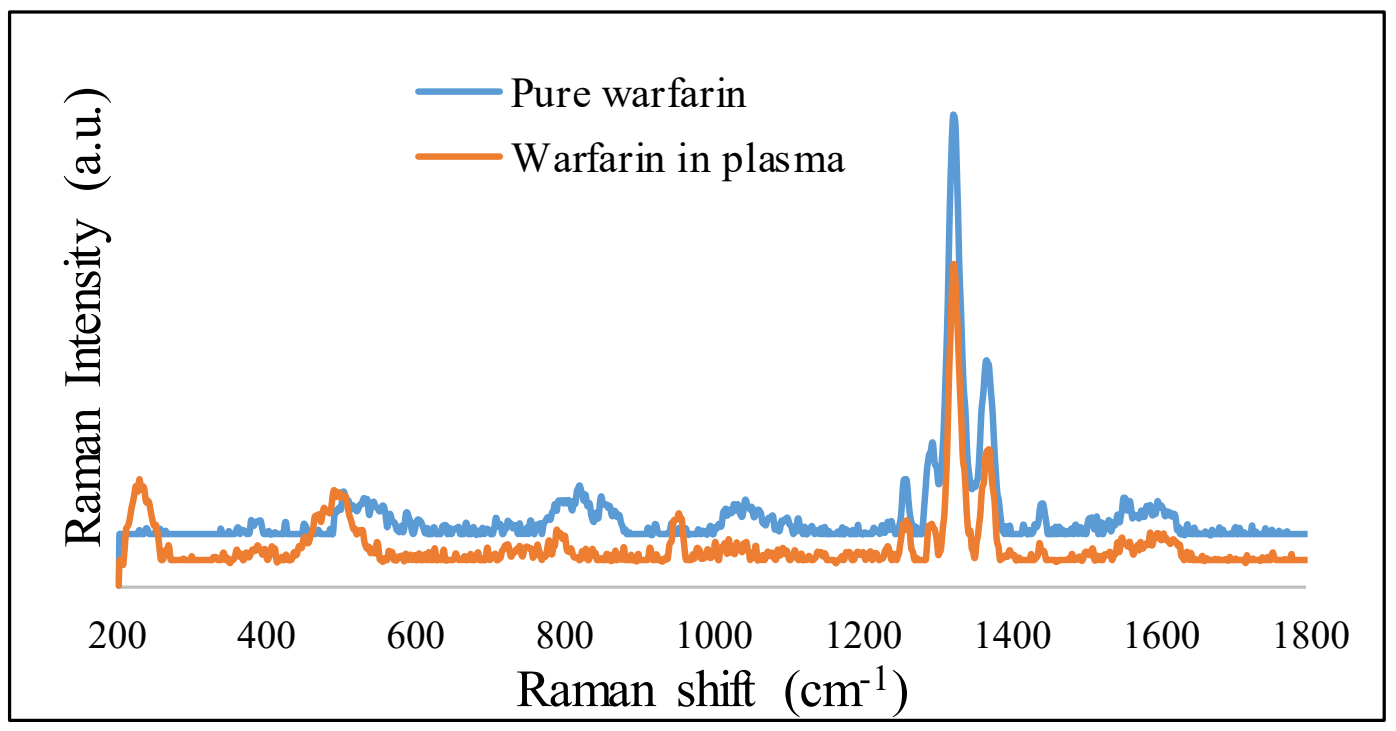

Figure S8. Baseline-corrected SERS spectra of pure warfarin in buffer pH 6.8 and in plasma mixed with PDDA-Ag citrate colloid obtained at $638 \mathrm{~nm}$ laser excitation wavelength. Spectra have been baseline corrected and offset for clarity. 
Table S3. Regression parameters obtained from calibration measurements for the detection of warfarin in pure form and in spiked plasma (shown in Figure 5 in the main manuscript) where RSD is the relative standard deviation and SE is the standard error.

\begin{tabular}{|l|c|c|}
\hline \multicolumn{1}{|c|}{ Parameters } & Pure form & Spiked plasma \\
\hline Concentration range $(\mathrm{nM})$ & $12.0-36.0$ & $12.0-25.0$ \\
\hline Limit of detection & 0.56 & 0.25 \\
\hline Limit of quantification & 1.70 & 0.77 \\
\hline Correlation coefficient & 0.9917 & 0.9971 \\
\hline Slope & 0.0097 & 0.019484 \\
\hline Intercept & 0.0902 & -0.09274 \\
\hline Standard deviation of residuals & 0.0016 & 0.0015 \\
\hline S.D. of intercept $\left(\mathrm{S}_{\mathrm{a}}\right)$ & 0.018777 & 0.01635 \\
\hline S.D. of slope $\left(\mathrm{S}_{\mathrm{b}}\right)$ & 0.000729 & 0.000863 \\
\hline \% RSD & 6.71 & 2.74 \\
\hline SE & 3.00 & 1.22 \\
\hline
\end{tabular}

In addition to regression slope analysis, the limit of detection (LOD) was determined by establishing the minimum level at which the analyte can be reliably detected. The limit of quantitation (LOQ) was determined by establishing the lowest concentration that can be measured according to ICH recommendations [10] below which the calibration graph is non-linear.

The values of LOD and LOQ were calculated according to the following equations:

$$
\mathrm{LOD}=. \sigma / \mathrm{S} \quad \mathrm{LOQ}=10 \sigma / \mathrm{S}
$$

where $\sigma=$ the residual standard deviation of the response and $\mathrm{S}=$ slope of the calibration curve. 
Table S4: Statistical analysis of the results of pure warfarin detected by the SERS method, compared with a standard HPLC method.

\begin{tabular}{|c|c|c|c|c|c|}
\hline \multirow[t]{7}{*}{ Parameter } & \multicolumn{3}{|c|}{ SERS method } & \multicolumn{2}{|c|}{$\begin{array}{c}\text { Standard HPLC method } \\
{[11]}\end{array}$} \\
\hline & $\begin{array}{c}\mathrm{nM} \\
\text { taken }\end{array}$ & $\begin{array}{l}\mathrm{nM} \\
\text { found }\end{array}$ & $\begin{array}{c}\% \\
\text { Recovery }\end{array}$ & $\mu \mathrm{gmL}^{-1}$ & $\%$ Recovery \\
\hline & 12 & 10.72 & 89.33 & 1.00 & 98.37 \\
\hline & 20 & 20.88 & 104.40 & 1.50 & 102.45 \\
\hline & 24 & 25.44 & 105.99 & 2.00 & 99.75 \\
\hline & 30 & 30.35 & 101.17 & 3.00 & 101.54 \\
\hline & 36 & 34.92 & 97.00 & & \\
\hline Mean $(\mathrm{X})$ & \multicolumn{3}{|c|}{99.58} & \multicolumn{2}{|c|}{100.53} \\
\hline$\pm \mathrm{SD}$ & \multicolumn{3}{|c|}{6.68} & \multicolumn{2}{|c|}{1.82} \\
\hline $\mathrm{N}$ & \multicolumn{3}{|c|}{5} & \multicolumn{2}{|c|}{4} \\
\hline Variance & \multicolumn{3}{|c|}{44.64} & \multicolumn{2}{|c|}{3.33} \\
\hline$F F$-test & \multicolumn{5}{|c|}{$0.27(2.36)^{*}$} \\
\hline Students $t$-test & \multicolumn{5}{|c|}{ 13.42(9.12)* } \\
\hline
\end{tabular}

\section{Each result is the average of three different separate determinations.}

* Figures between parentheses are the tabulated $F$ and $t$ values respectively at $\mathrm{P}$ $=0.05[12]$. 
Table S5: Repeatability and reproducibility data of the proposed SERS method for the determination of warfarin.

\begin{tabular}{|c|c|c|}
\hline \multirow{4}{*}{$\begin{array}{c}\text { Intra-day } \\
\text { precision }\end{array}$} & \% Mean Recovery & 102.04 \\
\cline { 2 - 3 } & $\pm \mathrm{SD}$ & 2.68 \\
\cline { 2 - 3 } & \%RSD & 2.63 \\
\cline { 2 - 3 } & $\mathrm{SE}$ & 1.52 \\
\hline \multirow{3}{*}{ Inter-day precision } & \% Mean Recovery & 101.84 \\
\cline { 2 - 3 } & $\pm \mathrm{SD}$ & 4.88 \\
\cline { 2 - 3 } & \%RSD & 2.77 \\
\cline { 2 - 3 } & $\mathrm{SE}$ & 4.80 \\
\hline
\end{tabular}

* Each result is the average of three different separate determinations.

Table S6: Results obtained by the proposed SERS analysis of warfarin in dosage form and in spiked human plasma.

\begin{tabular}{|c|c|c|}
\hline Parameter & Dosage form & Spiked plasma \\
\hline \% Found & 102.98 & 103.94 \\
& 101.55 & 96.64 \\
& 97.89 & 98.42 \\
& & 100.28 \\
& & 100.76 \\
\hline Mean \pm SD & $100.80 \pm 2.62$ & $100.01 \pm 2.74$ \\
\hline \%RSD & 2.60 & 2.74 \\
\hline
\end{tabular}

*Each result is the average of three different separate determinations 


\section{References:}

(1) Lee, P.; Meisel, D. Adsorption and surface-enhanced Raman of dyes on silver and gold sols. J. Phys. Chem., 1982, 86, 3391-3395.

(2) Gracie, K.; Correa, E.; Mabbott, S.; Dougan, J. A.; Graham, D.; Goodacre, R.; Faulds, K. Simultaneous detection and quantification of three bacterial meningitis pathogens by SERS. Chem. Sci., 2014, 5, 1030-1040.

(3) Van Lierop, D.; Krpetić, Ž.; Guerrini, L.; Larmour, I. A.; Dougan, J. A.; Faulds, K.; Graham, D. Positively charged silver nanoparticles and their effect on surface-enhanced Raman scattering of dye-labelled oligonucleotides. Chem. Commun., 2012, 48, 8192-8194.

(4) D'Souza, S.; Melo, J. A method for the preparation of coimmobilizates by adhesion using polyethylenimine. Enzyme Microb. Technol., 1991, 13, 508-511.

(5) Silva, T. R.; Brondani, D.; Zapp, E.; Cruz Vieira, I. Electrochemical sensor based on gold nanoparticles stabilized in poly (allylamine hydrochloride) for determination of vanillin. Electroanalysis, 2015, 27, 465-472.

(6) Turkevich, J.; Stevenson, P. C.; Hillier, J. A study of the nucleation and growth processes in the synthesis of colloidal gold. Discuss. Faraday Soc. , 1951, 11, 55-75.

(7) Bonnier, F.; Blasco, H.; Wasselet, C.; Brachet, G.; Respaud, R.; Carvalho, L. F. C.; Bertrand, D.; Baker, M. J.; Byrne, H. J.; Chourpa, I. Ultra-filtration of human serum for improved quantitative analysis of low molecular weight biomarkers using ATR-IR spectroscopy. Analyst, 2017, $142,1285-1298$.

(8) Rahman, Z.; Mohammad, A.; Akhtar, S.; Siddiqui, A.; Korang-Yeboah, M.; Khan, M. A. Chemometric Model Development and Comparison of R aman and $13 \mathrm{C}$ Solid-State Nuclear Magnetic Resonance-Chemometric Methods for Quantification of Crystalline/Amorphous Warfarin Sodium Fraction in the Formulations. J. Pharm. Sci., 2015, 104, 2550-2558.

(9) Griffen, J. A.; Owen, A. W.; Matousek, P. Quantifying low levels ( $<0.5 \% \mathrm{w} / \mathrm{w})$ of warfarin sodium salts in oral solid dose forms using Transmission Raman spectroscopy. J. Pharm. Biomed. Anal. , 2018, 155, 276-283.

(10) ICH. ICH Harmonized Tripartite Guidline, Validation of Analytical Procedures: Text and

Methodology, Q2 (R1), Parent Guideline on Methodology. International Conference on Harmonization, Geneva, Switzerland, 2005, 11-12.

(11) The British Pharmacopoeia, t. E. H. m. S. O., Vallender; 2019., M. L.: British pharmacopoeia, 2019.

(12) Miller, J.; Miller, J. C.: Statistics and chemometrics for analytical chemistry; Pearson Education, 2018. 